\title{
A CASE OF FACTITIOUS BLEEDING: MUNCHAUSEN'S SYNDROME
}

\author{
Emre Oner ${ }^{1}$, Mehmet Unlu², Burak Solgun³ ${ }^{3}$ Huseyin Kocyigit ${ }^{4}$, Pinar Cimen ${ }^{5}$
}

\section{HOW TO CITE THIS ARTICLE:}

Emre Oner, Mehmet Unlu, Burak Solgun, Huseyin Kocyigit, Pinar Cimen. "A Case of Factitious Bleeding: Munchausen's Syndrome". Journal of Evolution of Medical and Dental Sciences 2015; Vol. 4, Issue 48, June 15; Page: 8416-8419, DOI: $10.14260 /$ jemds/2015/1219

ABSTRACT: Munchausen's syndrome is a psychiatric disorder in which patients inflict on themselves an illness or injury for the primary purpose of assuming the sick role. These patients can present with many different complaints and clinical symptoms including self-inflicted bleeding. This report describes a case of lately diagnosed Munchausen's syndrome who presented with hemoptysis and developed hematochezia and hematuria during the hospitalization period. Physicians should always consider this rare disorder in cases presented with bleeding symptoms of unknown origin.

KEYWORDS: Munchausen's syndrome, Hemoptysis, Hematochezia, hematuria.

INTRODUCTION: Munchausen's syndrome is classified as a factitious disorder in the latest version of Diagnostic and Statistical Manual of Mental Disorders (DSM-5).(1) This disease is characterized by the intentional production or feigning of physical or psychological symptoms with a psychological need and for the main purpose of being treated like a medical patient.(1) Physicians working in the emergency departments are more likely to come across such patients and these patients can present with so many diverse complaints including self-inflicted bleeding symptoms.(2)

We hereby report a case of Munchausen's syndrome presented with the varying bleeding symptoms.

CASE REPORT: A 20-year-old unmarried female presented to the emergency department of our hospital with intermittent hemoptysis affecting her especially for the last three days. She denied a history of fever, upper or lower respiratory tract symptoms.

She had been studying at university since 2 years and her smoking history was 4 packs/year. There was no past history of a chronic disease and her family history was unremarkable. She had never consumed illicit drugs and had no allergies.

On admission, she had a respiratory rate of 15 breaths/minute, a blood pressure of 120/70 $\mathrm{mmHg}$, and a heart rate of about 78 beats/minute with sinus rythm. Chest auscultation revealed the presence of normal lung sounds. Examination of complete blood count (CBC) revealed normal values. Results of blood chemistry were within normal limits. Erythrocyte sedimentation rate was $10 \mathrm{~mm} / \mathrm{h}$ and serum level of C-reactive protein was $0.3 \mathrm{mg} / \mathrm{dl}$. The coagulation profile revealed normal results. Plasma level of D-dimer calculated by enzyme-linked immunosorbent assay was less than $500 \mu \mathrm{g} / \mathrm{L}$ and Well's score for pulmonary thromboembolism was 0.Posteroanterior and lateral radiographs of the chest were including normal findings (Figure 1). Contrast-enhanced computed tomography of the thorax, oral cavity examination and indirect laryngoscopy were normal. Fiberoptic bronchoscopy which was performed immediately after hospitalization demonstrated normal bronchial tree without a sign of bleeding. Gram stain and cultures of the bronchial washings did not reveal any infectious organism. Special stains and cultures for mycobacteria were also negative. 
She had no sign of a hemoptysis for two days after bronchoscopic examination. However, on the fourth day of in-hospital stay she developed hematochezia. She drew attention to blood on her bed sheet and was complaining of rectal bleeding with an approximately amount of 150 milliliters. She underwent upper and lower gastrointestinal endoscopic procedures which demonstrated no sign of pathology or bleeding.

The day after she developed hematuria. Analysis of the repeated urine samples which she gave alone in the closed toilet of her room revealed only microscopic hematuria without microalbuminuria or proteinuria. However, once she did not close the toilet's door and one of the nurses saw the patient disconnecting her intravenous (IV) catheter and drop blood into the urinecollection container. After this, IV catheter was taken out and all urine samples obtained under supervision of a nurse revealed normal results. Abdominopelvic and urinary tract ultrasounds were also normal. There was no pathological finding in direct radiography of the abdomen (Figure 2).

She was an only daughter of a three children family. She had two educated and employed bigger brothers. Her father visited her several times during the in-hospital stay. A family interview revealed a happy life which oriented us about her not to have a secondary gain with staying in the hospital. Her family members confessed that the patient has overwhelming desire to be noticed, and often behave dramatically or inappropriately to get attention. In addition, her mother confirmed that she had never seen her daughter during an active bleeding period and all these bleeding symptoms occurred when the patient was alone.

Based on the clinical findings and psychiatry consultation, the patient was diagnosed as Munchausen's syndrome. She was unexpectedly happy when we told that origin of her bleeding symptoms could not be clarified, which was consistent with the situation of la belle indifference. Although transfer to the psychiatry department and psychoterapy were recommended, she suddenly left the hospital same evening without permission.

DISCUSSION: Munchausen's syndrome is a psychiatric disorder that was first described by Richard Asher in 1951.(3)This disorder was named for Baron Karl Friedrich von Munchausen who was born in Germany, joined the Russian military, and was known to tell unreal and fantastic tales about the battles he participated in against the Ottoman Turks.(3)

This syndrome is a mental illness, in which the patient repeatedly acts as if he or she has a physical, emotional or cognitive disorder.(4) Patients with this disorder act this way because of an inner need to be seen as ill or injured and there is no intention to achieve a concrete benefit, such as financial gain.(4)The patients are even willing to undergo painful or risky tests and operations in order to get the sympathy or special attention given to people who are truly sick. Thus, it is also sometimes known as hospital addiction syndrome, thick chart syndrome, or hospital hopper syndrome.(5)Consistent with the literature, this patient was also fearless about undergoing invasive medical procedures. Besides, it was obvious that she had no secondary gain.

There are no reliable statistics regarding the prevalance of this disorder, but it is considered to be rare. Although any age group may be affected, most patients are female and between 20 and 40 years of age.(6) The exact cause of this syndrome is a subject of debate. Some theories suggest that a history of abuse or neglect as a child, or a history of frequent illnesses that required hospitalization might be factors in the development of the syndrome. Researchers are also studying a possible link to personality disorders, which are common in people with Munchausen's syndrome.(7)This patient was also a young female and possibly to have a histrionic personality disorder. 
Most patients presenting with this disorder are admitted to hospital through the emergency department because of the dramatic presentation of an apparently severe illnesses.(2) Several presentation forms are described in the literature. Majority of the patients are admitted to the hospital with neurologic, haemathologic and gastrointestinal disorders.(3) There are published case reports in the literature about presentation with self-induced hypoglycemia, Cushing's disease, asthmatic symptoms, major trauma, infection, pregnancy, hypertension, and bleeding as in this case report.(8-15)

Presence of symptoms only when the patient is alone or not being observed, appearance of new or additional symptoms following negative test results, being more comfortable in the hospital than you might think, and history of seeking treatment at different hospitals are the main characteristics of this disorder.(4) This case was fulfilling these indicators which oriented us to a possible diagnosis of a factitious disorder.

Treatment for Munchausen's syndrome usually involves psychiatric counseling to change the thoughts and behaviours that are causing the condition.(1) Cognitive-behavioural therapy, family therapy and group therapy are the possible treatment modalities of this disorder. Although there are no medicines to treat factitious disorders, they may be used to treat any related condition such as depression, anxiety, or a personality disorder.(4) However, it can be difficult because most people refuse to admit they have a problem and will not cooperate with suggested treatment plans, as seen in this case.

CONCLUSION: In conclusion, factitious causes should always be considered in unclarified origin of bleeding, especially in cases presented with dramatic but inconsistent medical history, and an unusual personal behaviour.

\section{REFERENCES:}

1. American Psychiatric Association. Diagnostic and Statistical Manual of Mental Disorders. 5th ed. Washington, DC: American Psychiatric Publishing; 2013.

2. Bayliss RI. The deceivers. Br Med J (Clin Res Ed). 1984 Feb 25; 288(6417): 583-584.

3. Asher R. Munchausen's syndrome. Lancet. 1951 Feb 10; 1(6650): 339-341.

4. Cleveland Clinic. Diseases and Conditions. Munchausen Syndrome. Available from: http: //my.clevelandclinic.org/health/diseases_conditions/hic_An_Overview_of_Factitious_Disorder s/hic_Munchausen_Syndrome.

5. Prakash J, Das RC, Srivastava K, Patra P, Khan SA, Shashikumar R. Munchausen syndrome: Playing sick or sick player. Ind Psychiatry J. 2014 Jan; 23(1): 68-70.

6. Jaghab K, Skodnek KB, Padder TA. Munchausen's Syndrome and Other Factitious Disorders in Children: Case Series and Literature Review. Psychiatry (Edgmont). 2006 Mar; 3(3): 46-55.

7. Alinejad NA, Oettel DJ. Factitious disorder as repeated diabetic ketoacidosis: a case report. Innov Clin Neurosci. 2011 Feb; 8(2): 41-47.

8. Roy M, Roy A. Factitious hypoglycemia. An 11-year follow-up. Psychosomatics. 1995 Jan-Feb; 36(1): 64-65.

9. Cizza G, Nieman LK, Doppman JL, Passaro MD, Czerwiec FS, Chrousos GP, et al. Factitious Cushing syndrome. J Clin Endocrinol Metab. 1996 Oct; 81(10): 3573-3577.

10. Baker CE, Major E. Munchausen's syndrome. A case presenting as asthma requiring ventilation. Anaesthesia. 1994 Dec; 49(12): 1050-1051. 


\section{CASE REPORT}

11. Meek SJ, Kendall J, Cornelius P, Younge PA. Munchausen syndrome presenting as major trauma. J Accid Emerg Med. 1996 Mar; 13(2): 137-138.

12. Park AJ, Scerri GV. Munchausen's syndrome--masquerading as necrotizing fasciitis. J R Soc Med. 1996 Mar; 89(3): 170P-171P.

13. Schwartz JG, Xenakis EM. Munchausen's syndrome and the laboratory. Self-injection of human chorionic gonadotropin. Arch Pathol Lab Med. 1995 Jan; 119(1): 85-88.

14. Greten T, Ritz E. Factitious hypertensive crisis (Munchausen syndrome). Nephrol Dial Transplant. 1996 May; 11(5): 893-894.

15. Uzuner S, Bahali K, Kurban S, Erenberk U, Cakir E. A pediatric case of factitious disorder with unexplained bleeding symptoms. Gen Hosp Psychiatry. 2013 Nov-Dec; 35(6): 679.e7-8.

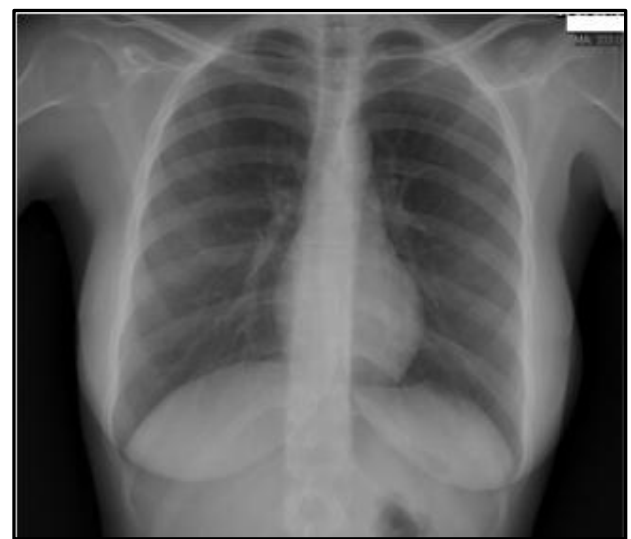

Fig. 1: Chest radiograph of the patient

\section{AUTHORS:}

1. Emre Oner

2. Mehmet Unlu

3. Burak Solgun

4. Huseyin Kocyigit

5. Pinar Cimen

\section{PARTICULARS OF CONTRIBUTORS:}

1. Senior Resident, Department of Emergency Medicine, Ankara University, School of Medicine.

2. Specialist, Department of Pulmonology, Luleburgaz State Hospital.

3. Senior Resident, Department of Emergency Medicine, Ankara University School of Medicine.

FINANCIAL OR OTHER COMPETING INTERESTS: None

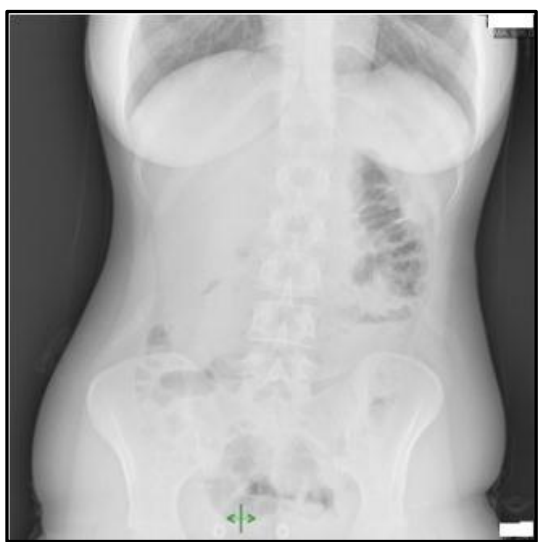

Fig. 2: Direct radiography of the abdomen

4. Senior Resident, Department of Emergency Medicine, Ankara University School of Medicine.

5. Associate Professor, Department of Pulmonology, Izmir Training \& Research Hospital for Thoracic Medicine \& Surgery.

\section{NAME ADDRESS EMAIL ID OF THE CORRESPONDING AUTHOR:}

Mehmet Unlu, Luleburgaz Devlet Hastanesi 2, Bina Gogus Hastaliklari Klinigi, Luleburgaz, Kirklareli, Turkiye. E-mail: lidokain21@hotmail.com

Date of Submission: 26/03/2015.

Date of Peer Review: 26/05/2015.

Date of Acceptance: 09/06/2015.

Date of Publishing: 15/06/2015. 